\title{
Prediction of genetic gains in body weight, egg production and shell quality traits in the Brown Tsaiya laying duck (Anas platyrhynchos)
}

\author{
YS Cheng ${ }^{1,2}$, JP Poivey ${ }^{1}, \mathrm{R}$ Rouvier ${ }^{1}, \mathrm{C}_{\text {Tai }}{ }^{2 *}$ \\ 1 Station d'amélioration génétique des animaux, \\ centre de recherches de Toulouse, Institut national de la recherche agronomique, \\ BP 27, 31326 Castanet-Tolosan cedex, France \\ 2 Taiwan Livestock Research Institute, 112 Farm Road Hsin-Hua, Tainan, \\ 71210 Taiwan, Republic of China
}

(Received 13 June 1995; accepted 16 August 1996)

Summary - An evaluation was made of the expected genetic gain and predicted genetic responses for egg weight and body weight at 40 weeks of age (EW40, BW40), number of eggs laid up to 52 weeks of age (NEGG52), eggshell strength at 30 or 40 weeks of age (ES30 or ES40) in Brown Tsaiya laying ducks selected for five generations by independent culling levels, first on a linear phenotypic index for the first three traits, and then on ES30 or ES40. The genetic parameters estimated in the base population were used to calculate the expected genetic gains in one generation of selection. The genetic responses per generation were evaluated by averaging the multitrait best linear unbiased prediction (BLUP) animal model predictors and regressing them on generation number. The per generation genetic responses were $+0.177 \mathrm{~g}($ EW40) $;+8.029 \mathrm{~g}$ (BW40); +0.935 eggs (NEGG52); +0.017 $\mathrm{kg} / \mathrm{cm}^{2}(\mathrm{ES} 30) ;+0.014 \mathrm{~kg} / \mathrm{cm}^{2}$ (ES40). These values fit the expected genetic gains for NEGG52, but they are higher than those for BW40 and lower than those for ES30 and ES40. It was shown that, compared to the selection method which has been used and with the same selection intensity in female ducks $(i=1.271)$, constrained selection based on a phenotypic selection index or a genetic index could increase the expected genetic gains in NEGG52 by a factor of 3.5 or 5.7, respectively, while maintaining constant EW40 and BW40.

genetic gain / selection / laying duck / restricted selection index

Résumé - Prédiction des gains génétiques sur des caractères de poids corporel, de production d'œufs et de qualité de la coquille chez la cane pondeuse Tsaiya Brune (Anas platyrhynchos). Les gains génétiques attendus et les réponses génétiques prédites du poids de l'œuf et du poids corporel à l'âge de 40 semaines (EW40, BW40), du nombre

* Correspondence and reprints 
d'œufs pondus jusqu'à l'âge de 52 semaines (NEGG52), de la solidité de la coquille aux âges de 30 et 40 semaines (ES30 ou ES40) chez la cane pondeuse Tsaiya Brune sélectionnée pendant cinq générations ont été calculés. La sélection par niveaux indépendants était basée sur un premier choix des $50 \%$ meilleures femelles d'après leurs valeurs individuelles d'un indice de sélection massale sur les trois caractères EW40, BW40, NEGG52 et sur un deuxième choix portant sur les valeurs individuelles de ES30 (deux premières générations) puis de ES4O à partir de la troisième génération. Les reproducteurs mâles étaient choisis de façon comparable à partir de l'information sur leurs sæurs. Au total, 3482 femelles et 2093 mâles ont été étudiés. Pendant les quatre premières générations, en moyenne $25,6 \%$ des femelles et $12,2 \%$ des mâles furent sélectionnés. À partir des paramètres génétiques de la population de base, les gains génétiques attendus ont été calculés. Les réponses génétiques par génération ont été estimées par ailleurs à partir des moyennes des prédicteurs de valeurs génétiques du BLUP modèle animal, en calculant la régression des moyennes en fonction du numéro de génération. Les réponses par génération sont de $+0,177 \mathrm{~g}(E W 40) ; \mathrm{de}+8,029 \mathrm{~g}$ (BW40); de + 0,935 oufs (NEGG52); de + 0,017 kg/ $\mathrm{cm}^{2}$ (ES30); de $+0,014 \mathrm{~kg} / \mathrm{cm}^{2}$ (ES40). Ces valeurs correspondent au gain génétique attendu pour NEGG52, elles sont plus fortes pour BW40 et plus faibles pour ES30 and ES4O. Il est montré que, par rapport à la méthode de sélection qui a été appliquée et avec la même intensité de sélection chez les canes $(\mathrm{i}=1,271)$, la sélection avec contraintes sur un indice de sélection massale ou un indice génétique sur quatre caractères pourrait multiplier le gain génétique attendu de NEGG52 par 3,5 et 5,7 respectivement, tout en maintenant constant le poids de l'œuf (EW40) et le poids corporel (BW40).

gain génétique / sélection / cane pondeuse / indice de sélection avec contraintes

\section{INTRODUCTION}

The native breed Brown Tsaiya (Anas platyrhynchos) is a major breed of laying duck in Taiwan. A selection for the four traits of egg weight and body weight at 40 weeks of age (EW40 and BW40), number of eggs laid up to 52 weeks of age (NEGG52), eggshell strength at 30 weeks of age (ES30, first two generations) and at 40 weeks of age (ES40, from generation three) has been conducted at the Ilan Branch of the Taiwan Livestock Research Institute since 1984. The selection was made by independent culling levels, first on the values of a restricted phenotypic selection index for three traits EW40, BW40, NEGG52 and then on the ES30 or ES40. There was no unselected control population. Cheng et al (1995) estimated the genetic parameters in the base population by REML applied to a multiple trait animal model based on data of the first five generations of selection. The selection goals of this breeding program at present are to maintain EW40 and BW40 at their current genetic levels, to increase as much as possible the genetic level in NEGG52, while getting a positive genetic response on ES30 and ES40. It is therefore useful at this stage to evaluate the genetic responses and to determine the most efficient multitrait selection index in order to get the desired gains.

From early research it is now well known that theoretically the selection index for several traits is more efficient than the independent culling levels procedure; the superiority may depend on the number of traits, the economic weights and the genetic correlations (Minvielle, 1990). Since Hazel (1943), the conventional selection index for multiple trait has been extended by several workers to take into account information from relatives (Henderson, 1963; Rouvier, 1969ab, 1977). 
One of the classical selection indices with restrictions for egg size, body weight and egg production rate in poultry selection was presented by Hogsett and Nordskog in 1958. The theory of restricted selection indices (Kempthorne and Nordskog, 1959) or indices for desired gains has been further developed (Mallard, 1972; Itoh and Yamada, 1987). When the means are unknown and the estimated variances and covariances used are not very different from their true values, multiple trait evaluation by best linear unbiased prediction (BLUP) can be used (Henderson and Quaas, 1976; Schaeffer, 1984; Ducrocq, 1994). Some applications with an animal model have been made recently by Hofer et al (1992) and Ducos (1994) for genetic evaluation in swine, and by Besbes (1993) for laying hens. A restricted BLUP, the BLUP counterpart of restricted selection index, has been derived by imposing restrictions on the multitrait mixed-model equations (MME) (Quaas and Henderson, 1976; Henderson, 1984). Lin (1990) gave a unified procedure for computing both a restricted BLUP and a restricted selection index for multiple trait (MT).

The purpose of this study was to predict the breeding value by an MT-BLUP procedure using an animal model in order to evaluate the genetic responses and to study the expected genetic gains calculated by the conventional methods. The results would then be used to discuss the possible application of a restricted genetic selection index for MT and maximum gain on the number of eggs laid up to 52 weeks of age.

\section{MATERIALS AND METHODS}

\section{Selection method}

A restricted selection index $I_{1}$ based on egg weight at 40 weeks of age in grams (EW40), body weight at 40 weeks of age in grams (BW40) and number of eggs laid up to 52 weeks of age (NEGG52) was first applied to select $50 \%$ of the female ducks. This restricted selection index was constructed with conventional estimated genetic parameters (table I) to increase the number of eggs while holding egg weight and body weight constant in Brown Tsaiya (Tai et al, 1994). As the heritabilities of ES30 and ES40, and their genetic correlations with the three previous traits were unknown, among these $50 \%$, the top $50 \%$ of the best female ducks was selected for ES30 in the first and second generations (G1 and G2) and for ES40 from the third generation (G3) of selection by independent culling levels. Eggs laid over five consecutive days at 30 and 40 weeks of age were weighed and measured by eggshell meters (unit: $\mathrm{kg} / \mathrm{cm}^{2}$ ) for the average of ES30 and ES40. The drakes were chosen within sire using information from four full sisters: first $35 \%$ of them on the averages of $I_{1}$ and then $35 \%$ on averages of ES30 or ES40. On average in G1 up to G4, $12.2 \%$ of the drakes and $25.6 \%$ of the female ducks were selected. In G1 up to G5, the data from 3482 female and 2093 male offspring were recorded (Cheng et al, 1995; table II).

\section{Computation of breeding values and predicted genetic responses}

Theoretically, an MT animal model which accounts for covariances among traits should reduce the prediction error variance of predicted breeding values (Schaeffer, 
Table I. Genetic parameters estimated by Cheng et al (1995), first line, and used in Tai et al (1994), second line.

\begin{tabular}{lrrrrr}
\hline Trait & EW40 & BW40 & NEGG52 & ES30 & ES40 \\
\hline EW40 & $\mathbf{0 . 3 2 9}$ & 0.424 & 0.060 & 0.173 & 0.132 \\
BW40 & $\mathbf{0 . 2 1 0}$ & & & & \\
& 0.617 & $\mathbf{0 . 4 9 9}$ & 0.063 & 0.118 & 0.064 \\
NEGG52 & 0.433 & $\mathbf{0 . 3 7 8}$ & & & \\
ES30 & -0.323 & 0.006 & $\mathbf{0 . 1 1 8}$ & -0.046 & -0.043 \\
ES40 & 0.401 & 0.529 & $\mathbf{0 . 1 5 7}$ & & \\
Phenotypic variances & 0.583 & 0.472 & -0.194 & $\mathbf{0 . 0 1 7}$ & 0.291 \\
& 0.483 & 0.231 & -0.203 & 0.845 & $\mathbf{0 . 0 9 4}$ \\
\end{tabular}

EW40: egg weight as 40 weeks of age in grams; BW40: body weight at 40 weeks of age in grams; NEGG52: number of eggs laid up to 52 weeks of age; ES30, ES40: eggshell strength at 30,40 weeks of age in $\mathrm{kg} / \mathrm{cm}^{2}$; phenotypic correlations: above the diagonal; genetic correlations: below the diagonal; heritabilities in the diagonal.

Table II. Structure of the selection experiment and inbreeding coefficient (means $\pm \mathrm{sd}$ ).

\begin{tabular}{|c|c|c|c|c|}
\hline Generation & $\begin{array}{c}\text { Number of } \\
\text { hatches }\end{array}$ & $\begin{array}{l}\text { Number of } \\
\text { offspring }^{\mathrm{a}}\end{array}$ & $\begin{array}{l}\text { Number of } \\
\text { parents }^{\mathrm{a}}\end{array}$ & Inbreeding coefficient \\
\hline G0 & & & $\begin{array}{l}M=40 \\
F=156\end{array}$ & 0 \\
\hline G1 & 5 & $\begin{array}{l}M=111 \\
F=537\end{array}$ & $\begin{array}{l}M=18 \\
F=121\end{array}$ & 0 \\
\hline G2 & 4 & $\begin{array}{l}M=161 \\
F=450\end{array}$ & $\begin{array}{l}M=34 \\
F=113\end{array}$ & 0 \\
\hline G3 & 5 & $\begin{array}{l}M=400 \\
F=449\end{array}$ & $\begin{array}{l}M=30 \\
F=117\end{array}$ & $0.0144 \pm 0.0223$ \\
\hline G4 & 6 & $\begin{array}{l}M=797 \\
F=934\end{array}$ & $\begin{array}{l}M=30 \\
F=108\end{array}$ & $0.0550 \pm 0.0208$ \\
\hline G5 & 6 & $\begin{array}{l}M=624 \\
F=1112\end{array}$ & $\begin{array}{l}M=31 \\
F=130\end{array}$ & $0.0485 \pm 0.0255$ \\
\hline Total & 26 & $\begin{array}{l}M=2093 \\
F=3482\end{array}$ & & $0.033 \pm 0.031$ \\
\hline
\end{tabular}

${ }^{\text {a }}$ Parents of the offspring of the next generation; $M=$ number of males, $F=$ number of females; BW40 was measured on males and females; ES30 was measured in generations G1 up to G3; ES40 was measured from G3 up to G5.

1984; Thompson and Meyer, 1986). Therefore, the same data for the five traits (EW40, BW40, NEGG52, ES30 and ES40), the heritabilities and phenotypic and genetic correlations estimates for these five traits were taken from Cheng et al (1995) for computation of breeding values (table I). The pedigree information was traced 
to the founder animals (G0) which were assumed to be unrelated (table II). Hatch batches (26 levels) and sexes (for BW40) were assigned as fixed effects. Predicted breeding values of the five traits were calculated by an MT-BLUP animal model that accounts for inbreeding using the PEST program (Groeneveld, 1990; Groeneveld and Kovac, 1990; Groeneveld et al, 1992). The genetic responses for each trait were estimated from the regression of the MT-BLUP breeding values of female ducks on generation number. The phenotypic selection differentials for each trait were calculated in female ducks only.

\section{Multitrait selection index and expected genetic gains}

The expected genetic gains for one generation which correspond to the applied selection index, have to be calculated in order to compare them with the predicted genetic response. They also have to be calculated when selecting on multitrait selection index to make possible improvement of the selection efficiency. The expected genetic gain in each traits was based on the regression of its additive genetic value on the selection differential in the selection index.

\section{Selection on individual phenotypic values}

In the present case the selection was based on a restricted phenotypic selection index $I_{1}=\mathbf{b}^{\prime} \mathbf{y}$ for the three traits EW40, BW40 and NEGG52. The vector $\mathbf{b}$ was chosen in order to fit the restrictions of no genetic change for EW40 and BW40.

\section{Selection on the predicted individual breeding values}

If $\widehat{\mathbf{g}}$ is the vector of predictors of breeding values for each of the $n$ traits of an animal, it is straightforward, according to the classical theory (Rouvier, 1969ab, 1977; Mallard, 1972), to combine them in a genetic index $I_{g}=\mathbf{a}^{\prime} \widehat{\mathbf{g}}$ where $\mathbf{a}$ is the vector of coefficients for the $n$ breeding values, $\mathbf{a}^{\prime}$ is a transposed, and $\widehat{\mathbf{g}}$ is the vector of predictors of breeding values for each of the $n$ traits, calculated as the multiple regression of $\mathbf{g}$ on all the phenotypic predictors.

Following $\operatorname{Lin}(1990)$ the vector of the coefficients in the restricted genetic index $I_{2}=\mathbf{v}^{\prime} \hat{\mathbf{g}}$ has been calculated with constraints of 0.0 and $0.013 \mathrm{~kg} / \mathrm{cm}^{2}$ for genetic gains in EW40, BW40 and ES40 respectively and maximum gain in NEGG52 (with a selection intensity $i=1$ ).

The matrix of additive genetic variances and covariances of the $n$ traits was assumed to be known. The matrix $E\left(\widehat{\mathbf{g}} \widehat{\mathbf{g}}^{\prime}\right)=\mathbf{B}$ was approximated by $\widehat{\mathbf{B}}$, the variance-covariance matrix of the MT-BLUP breeding values in an animal model.

\section{RESULTS}

\section{Expected genetic gains for the selection method used}

Table III gives the expected genetic gains for female ducks in one generation for EW40, BW40, NEGG52, ES30 and ES40 when selecting by independent culling level on the index $I_{1}$ with $p=50 \%$, and on ES30 or ES40 with $p=50 \%$. Since 
$I_{1}$ and ES30 or ES40 are phenotypically uncorrelated, the formulas of Young and Weiler (1961) simplify to calculate the selection intensities which are $i=0.789$ for $I_{1}$ and the same for ES30 or ES40. In total $25 \%$ of the female ducks are theoretically selected with this procedure. The expected genetic gains for male ducks in one generation are similar, being $+0.595,+0.490$ for EW40, $+5.245,-1.290$ for $\mathrm{BW} 40,+0.974,+0.993$ for NEGG52, +0.051, +0.040 for ES30, + 0.058, + 0.063 for ES40, when selecting in the second step for ES30 or ES40 respectively. The overall expected gains can be obtained by averaging the second figures with the corresponding ones in the last two lines of table III.

Table III. Expected genetic gains for EW40, BW40, NEGG52, ES30 and ES40 in female ducks in one generation by selecting with independent culling level on $I_{1}=0.099$ EW40 -0.00277 BW40 + 0.026 NEGG52 and ES30 or ES40 with $p=50 \%$ selected in each case (final $p=25 \%$ ), phenotypic correlation between $I_{1}$ and ES30, ES40, $r p=0)$.

\begin{tabular}{lrrrrr}
\hline \multirow{2}{*}{ Trait selected } & \multicolumn{5}{c}{ Expected response } \\
\cline { 2 - 6 } & $E W 40$ & $B W 40$ & NEGG52 & ES30 & ES40 \\
\hline Selecting $p=50 \%$ on $I_{1}$ & 0.119 & -6.463 & 1.432 & -0.0005 & 0.005 \\
Selecting $p=50 \%$ on ES30 & 0.443 & 11.436 & -0.500 & 0.0490 & 0.048 \\
Selecting $p=50 \%$ on ES40 & 0.342 & 5.236 & -0.490 & 0.0380 & 0.053 \\
Total expected genetic gain $p=25 \%$ & & & & \\
Selecting $p=50 \%$ ES30 & 0.562 & 4.973 & 0.932 & 0.0485 & 0.052 \\
Selecting $p=50 \%$ ES40 & 0.461 & -1.227 & 0.942 & 0.037 & 0.058 \\
\hline
\end{tabular}

EW40, BW40, NEGG52, ES30 and ES40: see table I.

\section{Predicted genetic responses}

Table IV gives the average phenotypic values in Brown Tsaiya female ducks for EW40, BW40, NEGG52, ES30 and ES40 for the five generations (G1 to G5). It also gives the phenotypic values of the selected animals and the achieved phenotypic selection differential. The genetic responses in female ducks for MT-BLUP animal model prediction are shown in figure 1 and table $\mathrm{V}$.

\section{Genetic selection indices}

The (co)variances of the predicted breeding values for EW40, BW40, NEGG52 and ES40 were calculated for males and females in the generation to be selected (fifth generation, table VI). From these parameters, the restricted genetic selection indices $I_{2}$ were calculated separately for male and female ducks of G5. The results are shown in table VII for the coefficients of the predictors of breeding values and the expected genetic gains in each trait, by a truncation selection with selection intensity $i=1$. The expected gains for a similarly restricted phenotypic selection index $\left(I_{3}\right)$ are also included in table VII. 
Table IV. The average phenotypic values and selection differential for EW40, BW40, NEGG52, ES30 and ES40 of Brown Tsaiya female ducks for five generations.

\begin{tabular}{|c|c|c|c|c|c|}
\hline Generations & $E W 40(\mathrm{~g})$ & $B W 40(g)$ & NEGG52 (eggs) & $\operatorname{ES} 30\left(\mathrm{~kg} / \mathrm{cm}^{2}\right)$ & $E S 4 O\left(\mathrm{~kg} / \mathrm{cm}^{2}\right)$ \\
\hline $\begin{array}{l}\text { G1 } \\
\quad \text { (S) } \\
\quad \text { (I) }\end{array}$ & $\begin{array}{l}69.3 \\
67.8\end{array}$ & $\begin{array}{l}1377 \\
1407\end{array}$ & $\begin{array}{l}222.9 \\
208.6\end{array}$ & $\begin{array}{l}4.2 \\
3.8\end{array}$ & - \\
\hline $\begin{array}{l}\text { Selection differential } \\
\text { G2 }\end{array}$ & +1.5 & -30 & +14.3 & +0.4 & \\
\hline $\begin{array}{l}\text { (S) } \\
(\mathrm{I})\end{array}$ & $\begin{array}{l}68.5 \\
67.4\end{array}$ & $\begin{array}{l}1340 \\
1327\end{array}$ & $\begin{array}{l}231.6 \\
220.9\end{array}$ & $\begin{array}{l}4.2 \\
3.8\end{array}$ & - \\
\hline $\begin{array}{l}\text { Selection differential } \\
\text { G3 }\end{array}$ & +1.1 & +13 & +10.7 & +0.4 & \\
\hline $\begin{array}{l}\text { (S) } \\
\text { (I) }\end{array}$ & $\begin{array}{l}70.9 \\
68.2\end{array}$ & $\begin{array}{l}1418 \\
1384\end{array}$ & $\begin{array}{l}219.3 \\
206.6\end{array}$ & $\begin{array}{l}4.1 \\
3.9\end{array}$ & $\begin{array}{l}3.9 \\
3.6\end{array}$ \\
\hline $\begin{array}{l}\text { Selection differential } \\
\text { G4 }\end{array}$ & +2.7 & +34 & +12.7 & +0.2 & +0.3 \\
\hline $\begin{array}{l}\text { (S) } \\
\text { (I) }\end{array}$ & $\begin{array}{l}68.8 \\
67.5\end{array}$ & $\begin{array}{l}1414 \\
1392\end{array}$ & $\begin{array}{l}224.7 \\
204.5\end{array}$ & - & $\begin{array}{l}3.8 \\
3.6\end{array}$ \\
\hline $\begin{array}{l}\text { Selection differential } \\
\text { G5 }\end{array}$ & +1.3 & +22 & +20.2 & & +0.2 \\
\hline $\begin{array}{l}\text { (S) } \\
(\mathrm{I})\end{array}$ & $\begin{array}{l}69.9 \\
68.8\end{array}$ & $\begin{array}{l}1482 \\
1466\end{array}$ & $\begin{array}{l}217.3 \\
198.8\end{array}$ & - & $\begin{array}{l}4.0 \\
3.4\end{array}$ \\
\hline Selection differential & +1.1 & +16 & +18.5 & & +0.6 \\
\hline
\end{tabular}

EW40, BW40, NEGG52, ES30 and ES40: see table I. (S): value of selected individuals; (I): value of individual candidates.

Table V. Average genetic response in female ducks from multitrait BLUP animal model predictions.

\begin{tabular}{lccc}
\hline \multirow{2}{*}{ Trait } & \multicolumn{2}{c}{ Average genetic response per generation } \\
\cline { 2 - 4 } & In actual units & $\begin{array}{c}\text { Percentage of the mean } \\
\end{array}$ & $\begin{array}{c}\text { Percentage of the genetic } \\
\text { standard deviation }\end{array}$ \\
\hline EW40 $(\mathrm{g})$ & $+0.177 \pm 0.001$ & 0.26 & 6.1 \\
BW40 $(\mathrm{g})$ & $+8.029 \pm 0.095$ & 0.58 & 8.6 \\
NEGG52 $(\mathrm{eggs})$ & $+0.935 \pm 0.003$ & 0.45 & 9.4 \\
ES30 $\left(\mathrm{kg} / \mathrm{cm}^{2}\right)$ & $+0.017 \pm 0.003$ & 0.45 & 9.3 \\
ES40 $\left(\mathrm{kg} / \mathrm{cm}^{2}\right)$ & $+0.014 \pm 0.0015$ & 0.39 & 6.3 \\
\hline
\end{tabular}

EW40, BW40, NEGG52, ES30 and ES40: see table I.

\section{DISCUSSION}

When there is no control population, the genetic response per generation can be obtained by the regression of the average predicted genetic values of the ducks of the same generation on generation number. This method to estimate genetic trends 

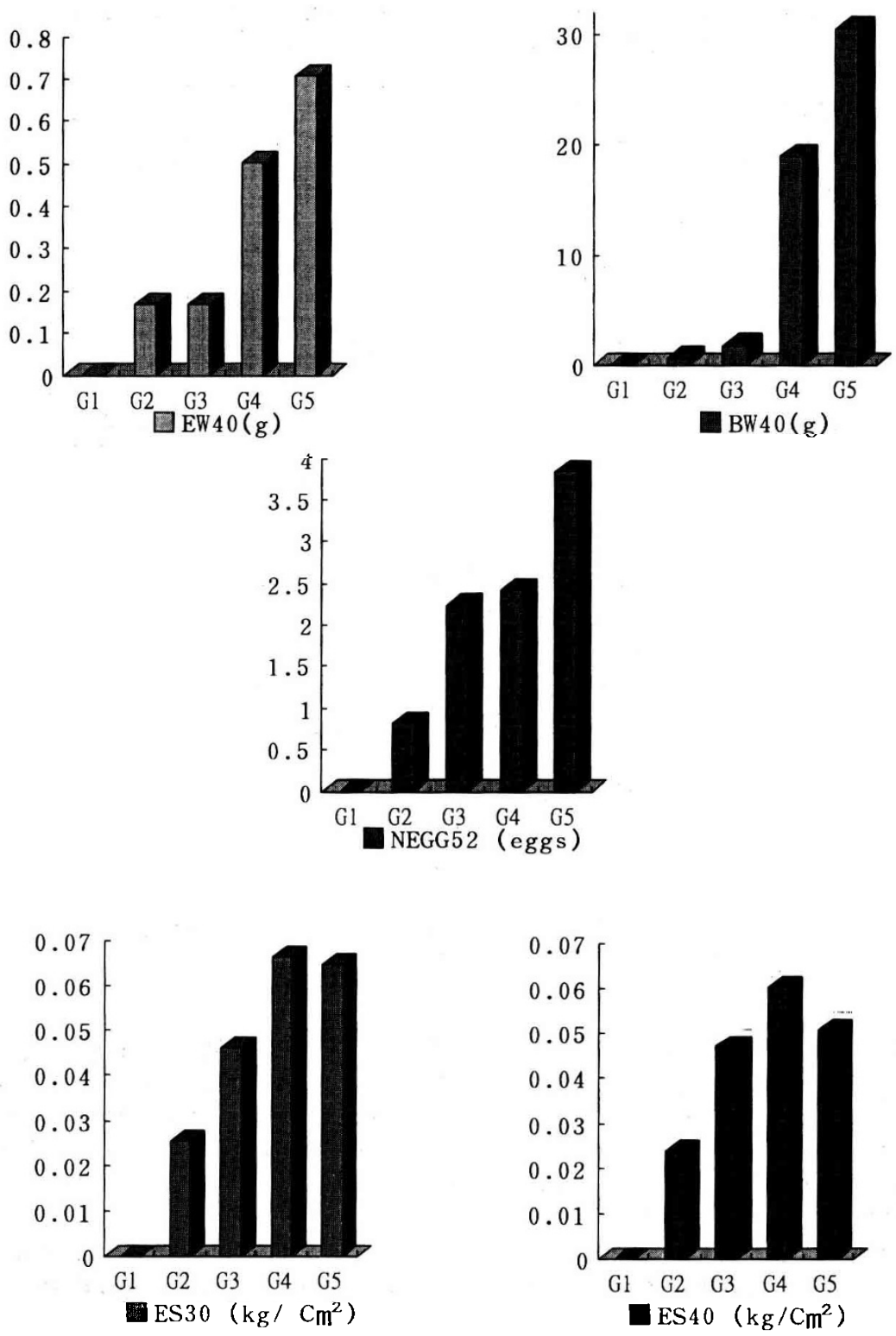

Fig 1. The average predicted additive genetic values per generation in female ducks for multitrait BLUP animal model predictions for EW40, BW40, NEGG52, ES30 and ES40. 
Table VI. Matrix of (co)variances of breeding values predicted by multivariate BLUP animal model for EW40, BW40, NEGG52 and ES40 (generation G5).

\begin{tabular}{|c|c|c|c|c|c|}
\hline G5 & $E W 40$ & $B W 40$ & NEGG52 & & $S 40$ \\
\hline EW40 & $\begin{array}{ll} & 3.221 \\
2.295 & \end{array}$ & 83.316 & -3.912 & 0.1291 & \\
\hline BW40 & 61.155 & $3_{595.920}^{4802.330}$ & -2.875 & & 2.4367 \\
\hline NEGG52 & -2.462 & 0.974 & 32.276 & & -0.3828 \\
\hline ES40 & 0.0794 & 1.1881 & -0.3166 & 0.0122 & 0.0156 \\
\hline
\end{tabular}

EW40, BW40, NEGG52 and ES40: see table I; (co)variances of females above the diagonal; (co)variances of males below the diagonal.

Table VII. Restricted selection indices in male and female ducks and expected genetic gains in each trait with selection intensity $i=1$.

\begin{tabular}{lcccccccc}
\hline Index number & \multicolumn{4}{c}{ Coefficient } & \multicolumn{4}{c}{ Expected genetic gain } \\
\cline { 2 - 9 } & $E W 40$ & $B W 40$ & NEGG52 & ES40 & EW40 & BW40 & NEGG52 & ES40 \\
\hline Male $\left(I_{2}\right)$ & 0.04318 & -0.00137 & 0.06626 & 1.85909 & 0 & 0 & 3.707 & 0.013 \\
Female $\left(I_{2}\right)$ & 0.05029 & -0.00150 & 0.05238 & 1.30168 & 0 & 0 & 4.211 & 0.013 \\
Female $\left(I_{3}\right)$ & 0.01592 & -0.00040 & 0.01253 & 0.15904 & 0 & 0 & 2.611 & 0.013 \\
\hline
\end{tabular}

$I_{2}$ : genetic selection index with restrictions $\mathrm{EW} 40=0, \mathrm{BW} 40=0, \mathrm{ES} 40=+0.013 \mathrm{~kg} / \mathrm{cm}^{2}$;

$I_{3}$ : phenotypic selection index with the same constraints.

is unbiased because the genetic evaluation is based on a multitrait animal model (Henderson, 1975; Sorensen and Kennedy, 1984; Kennedy et al, 1988; Ducrocq, 1994). The predicted genetic response depends on the genetic parameters which have been used (Thompson, 1986). These were obtained by Cheng et al (1995) as unbiased estimates in the base population. These estimates were assumed to be not very different from the true values.

As far as we know, there is no published data from a selection experiment for such laying traits in laying female ducks. Recently, Besbes (1993) estimated the genetic trends in two strains of laying hens selected for egg production, egg quality and body weight traits, by the regression of the average values of the predictors of breeding values above ten separate generations with several hatch fixed effects in each one.

The model of analysis was based on the prediction of the additive genetic values, without taking account dominance effects. In case of dominance, as for egg number traits in this population (Tai et al, 1989), the genetic response might be overestimated (Johansson et al, 1994). 
In order to discuss in retrospect the efficiency of the selection method which was applied and to predict the efficiency of a new one to reach the current selection goals, the predicted genetic responses and the expected genetic gains were calculated. This second method can be applied in only one generation to predict the efficiency of the selection method. The first one takes into account the realized selection differentials and is unbiased by the selection.

The average genetic response per generation for the number of eggs laid up to 52 weeks of age (NEGG52) represents $9.4 \%$ of the additive genetic standard deviation. It is close to the expected genetic gain (0.953 to 0.967 eggs). Nevertheless, the phenotypic trend for NEGG52 is negative dropping from 208.6 eggs in G1 to 198.8 eggs in G5, This could be explained by an adverse environmental effect especially in G5 with larger change of climate in the open feeding system (it was 217 eggs in G6). On the other hand, the increase in inbreeding coefficient is rather small, the mean \pm standard deviation being $0.0485 \pm 0.0255$ in G5. The founder animals are assumed to be neither inbred nor related (table II). The genetic response in EW40 represents $6.1 \%$ of the additive genetic standard deviation of the trait. This slight increase may be due to the selection for ES30 and ES40, which are positively correlated to EW40 $\left(r_{g}=0.583\right.$ and $r_{g}=0.483$, respectively). The genetic response in BW40 (8.6\% of the additive genetic standard deviation) was higher than the expected genetic gain. When selecting for ES30 or ES40, there was a correlated positive response on BW40 which counteracted the effects of the selection on $I_{1}$. As has already been observed by Lee et al (1991, 1993), the eggshell strength depended on the age of the ducks and ES40 was weaker on average than ES30. From G3 the selection criterion ES30 was replaced by ES40 (Lee et al, 1992). The genetic responses per generation in ES30 $\left(+0.017 \mathrm{~kg} / \mathrm{cm}^{2}\right)$ and in ES40 $\left(+0.014 \mathrm{~kg} / \mathrm{cm}^{2}\right)$ were lower than the expected ones. The genetic responses per generation in ES30 and ES40 were 9.3 and $6.3 \%$ respectively of the additive genetic standard deviations of the traits.

More than $90 \%$ of eggs produced is used for egg processing such as salted eggs and century eggs in Taiwanese markets. Economically speaking, a small body size of female duck is desirable to reduce maintenance requirements and egg weight has to be maintained at the current level (around $65 \mathrm{~g}$ ) to meet market requirements, ES30 and ES40 must not be decreased in order to maintain a low incidence of broken eggs. Thus, NEGG52 has to be increased without negative correlated response on these two traits. The genetic correlations between NEGG52 and ES30 or ES40 are small and negative $\left(r_{g}=-0.194\right.$ and $r_{g}=-0.203$, respectively). The selection method applied was rather efficient for the desired gains in ES30 and ES40 and there was a positive genetic response in EW40 and BW40. The method however was not efficient for improving NEGG52. This could be explained by the independent culling on ES30 and ES40 of $50 \%$ of female ducks selected for $I_{1}$. According to the heritabilities and the genetic correlations, this independent culling induces a negative correlated genetic response in NEGG52 and a positive correlated genetic responses in EW40 and BW40 (table III). This is similar for the male duck selection.

Since ES40 is measured before NEGG52, it would be possible to use a multitrait selection index based on the four traits of EW40, BW40, NEGG52 and ES40 such as the phenotypic selection index $I_{3}$ (table VII). This selection index should improve the efficiency of the selection method. With $i=1.271$ ( $25 \%$ of selected female 
ducks), the expected genetic progress on NEGG52 would be multiplied by a factor of 3.5 compared with the current selection method.

A simple computation procedure was derived to calculate a genetic multitrait selection index with restricted traits $I_{2}=\mathbf{v}^{\prime} \widehat{\mathbf{g}}$ using the multitrait predictors $(\widehat{\mathrm{g}})$ of breeding values. The performance data of the 3482 female ducks and 2093 males (for BW40) of the five generations were taken into account for calculating the matrix $\widehat{\mathbf{B}}$ of variances and covariances of the predicted breeding values of all the animals in G5 (1112 females and 624 males), separately for males and females with the assumption $E(\widehat{\mathbf{B}})=\mathbf{B}$. This assumption is more valid when there is a large number of animals. Theoretically, the variances of each predictor for each animal depend on the coefficients of relationship with its relatives which are not the same for each animal. So the approximation of one unique average $\widehat{\mathbf{B}}$ has to be made. The results revealed (table VII) that with $i=1.271$ the expected genetic gain for NEGG52 was multiplied by the factor 5.7, when compared with selection by independent culling levels. This extra gain compared to $I_{3}$ is explained by the increase in accuracy of the prediction of breeding values and of the multitrait genetic selection index. The application of this method would lead to variance-covariance matrix of the MTBLUP animal model predictors of breeding values calculated separately for males and females in the generation to be selected.

\section{CONCLUSIONS}

The selection method applied for five generations in laying Brown Tsaiya ducks has resulted in a predicted genetic response per generation of +0.935 eggs for the number of eggs laid up to 52 weeks of age. It is the only trait for which the genetic response fits the expected genetic gain. The genetic responses were higher than expected for BW40, but lower than expected for ES30 and ES40. Assuming that the estimates of the genetic parameters in the base population were accurate, it was shown that a restricted selection index based on phenotypic values of four traits EW40, BW40, NEGG52 and ES40 would fit the breeding objectives better than the independent culling level method; EW40 and BW40 could be maintained at their current genetic level, the expected genetic gains in NEGG52 should be much higher and the expected genetic gains on ES30 and ES40 should be positive as desired. Due to the increased accuracy of the predictors of breeding values using an MT-BLUP animal model, a restricted genetic selection index will given even larger expected genetic gain for NEGG52 compared to a conventional restricted selection index. So this selection procedure could be recommended.

\section{ACKNOWLEDGMENTS}

This study was undertaken as a cooperative research project between the Council of Agriculture-Taiwan Livestock Research Institute from the Taiwan Provincial Department of Agriculture and Forestry (COA-TLRI) and the Institut national de la recherche agronomique-Station d'amélioration génétique des animaux du département de génétique animale (INRA-SAGA). We would like to thank all the staff at TLRI (especially Ilan Sub-Institute of TLRI) and SAGA for their help in carrying out this research and also INRA-SAGA and COA-TLRI for their financial support. 


\section{REFERENCES}

Besbes B (1993) Evaluation de souches de poules pondeuses à l'aide de la méthodologie $\mathrm{du}$ BLUP. Thèse de doctorat en sciences, Institut national agronomique Paris-Grignon, France

Chen YS, Rouvier R, Poivey JP, Tai C (1995) Genetic parameters of body weight, egg production and shell quality traits in the laying Brown Tsaiya duck. Genet Sel Evol $27,459-472$

Ducos A (1994) Evaluation génétique des porcs contrôlés dans les stations publiques à l'aide d'un modèle animal multicaractères. Thèse de doctorat en sciences, Institut national agronomique Paris-Grignon, France

Ducrocq V (1994) Multiple trait prediction: principles and problems. Proceedings of the 5th World Congress on Genetics Applied to Livestock Production, August 7-12, University of Guelph, Guelph, Ontario, Canada, vol 18, 455-462

Groeneveld E (1990) PEST User's Manual. Department of Animal Sciences, University of Illinois, Urbana, IL, USA

Groeneveld E, Kovac M (1990) A generalized computing procedure for setting up and solving mixed linear models. J Dairy Sci 73, 513-531

Groeneveld E, Kovac M, Wang TL, Fernando RL (1992) Computing algorithms in a general purpose BLUP package for multivariate prediction and estimation. Arch Tierz Dummerstorf 35, 399-412

Hazel LN (1943) The genetic basis for constructing selection indexes. Genetics 28, 476-490

Henderson CR (1963) Selection index and expected genetic advance. In: Statistical Genetics and Plant Breeding, (WD Hanson, HF Robinson ed), National Academy of Sciences-National Research Council, Washington, DC, publication 982, 141-163

Henderson CR (1975) Best linear unbiased estimation and prediction under a selection model. Biometrics 31, 423-477

Henderson CR, Quaas RL (1976) Multiple trait evaluation using relatives records. J Anim Sci $43,1188-1197$

Henderson CR (1984) Application of Linear Models in Animal Breeding. University of Guelph, Guelph, Canada

Hofer A, Hagger C, Kunzi N (1992) Genetic evaluation of on-farm tested pigs using an animal model. II. Prediction of breeding values with a multiple trait model. Livest Prod Sci 30, 83-98

Hogsett ML, Nordskog AW (1958) Genetic-economic value in selecting for egg production rate, body weight and egg weight. Poult Sci 37, 1404-1419

Itoh Y, Yamada Y (1987) Comparisons of selection indices achieving predetermined proportional gains. Génét Sél Evol 19, 69-82

Johansson K, Kennedy BW, Wilhelmson M (1994) Precision and bias of estimated genetic parameters in the presence of dominance and inbreeding. Proceedings of the 5th World Congress on Genetics Applied to Livestock Production, August 7-12, University of Guelph, Guelph, Ontario, Canada, vol 18, 386-389

Kempthorne O, Nordskog AW (1959) Restricted selection indices. Biometrics 15, 10-19

Kennedy BW, Schaeffer LR, Sorensen DA (1988) Genetic properties of animal models. $J$ Dairy Sci 71 (suppl 2), 17-26

Lee SR, Pan ST, Shyu ST, Chen BJ (1991) Study on the cage-feeding system for laying Tsaiya duck (Anas platyrhynchos var Domestica). Taiwan Livest Res 24, 177-185

Lee SR, Huang JF, Sheu NS, Chen SY, Chen BJ, Jiang YN, Tai LJJ, Tai C (1992) Study on the performance of Brown Tsaiya duck (Anas platyrhynchos var Domestica). Taiwan Livest Res 25, 35-48 
Lee SR, Chen MC, Chen BJ (1993) Genetic study for laying interval in Brown Tsaiya duck (Anas platyrhynchos var Domestica). Taiwan Livest Res 26, 61-66

Lin CY (1990) A unified procedure of computing restricted best linear unbiased prediction and restricted selection index. J Anim Breed Genet 107, 311-316

Mallard J (1972) La théorie et le calcul des index de sélection avec restrictions: synthèse critique. Biometrics 28, 713-735

Minvielle F (1990) Principes d'amélioration génétique des animaux domestiques. INRA, Paris, Les presses de l'Université de Laval, Quebec

Quaas RL, Henderson CR (1976) Selection criteria for altering the growth curve. J Anim Sci 43, 221

Rouvier R (1969a) Contribution à l'étude des index de sélection sur plusieurs caractères. Thèse de doctorat en $3^{\mathrm{e}}$ cycle, Faculté des sciences, Paris

Rouvier $\mathrm{R}$ (1969b) Pondération des valeurs génotypiques dans la sélection par index sur plusieurs caractères. Biometrics 25, 295-307

Rouvier R (1977) Mise au point sur le modèle classique d'estimation de la valeur génétique. Ann Génét Sél Anim 9, 17-26

Schaeffer LR (1984) Sire and cow evaluation under multiple trait models. J Dairy Sci 67 , $1567-1580$

Sorensen DA, Kennedy BW (1984) Estimation of response to selection using least squares and mixed model. J Anim Sci 58, 1097-1106

Tai C, Rouvier R, Poivey JP (1989) Genetic parameters of some growth and egg production traits in laying Brown Tsaiya (Anas platyrhynchos). Genet Sel Evol 21, 377-384

Tai C, Huang YJ, Tai LJJ, Chyr SC (1994) The construction of constraint selection indices in laying ducks. J Chin Soc Anim Sci 23, 355-360

Thompson R (1986) Estimation of realized heritability in a selected population using mixed model methods. Genet Sel Evol, 18, 475-484

Thompson R, Meyer K (1986) A review of theoretical aspects in the estimation of breeding values for multitrait selection. Livest Prod Sci 15, 299-313

Young SSY, Weiler H (1961) Selection for two correlated traits by independent culling levels. J Genet 57, 329-338 